\title{
Caracterização mineralógica de argilas moles presentes nos arredores da reserva natural de Guaratiba: zona oeste do município do Rio de Janeiro
}

A expansão desenfreada dos grandes centros, bem como a falta de estudos mais aprofundados, acarretaram na crescente ocupação de áreas irregulares, assim como acontece hoje nas ultimas áreas de manguezais da reserva natural de Guaratiba. A argila mole, muito presente na costa brasileira, sempre proporciona um desafio, quanto à análise do seu comportamento, pois áreas próximas e com presença de espessuras consideráveis de argila mole, podem apresentar comportamentos geomecânicos distintos. Com a finalidade de contribuir para melhor compreensão do comportamento das arligas moles, bem como aprofundar os estudos nessas áreas de preservação, tão importantes para a manutenção do bioma local, o presente estudo aprofunda o conhecimento sobre a mineralogia dos solos da Zona Oeste do Rio de Janeiro. Foram realizados ensaios de difração de raio-x nas profundidades entre $4 \mathrm{~m}$ e $6 \mathrm{~m}$, das nove amostras analisadas, bem como ensaios de fluorescência de raios $-x$, com a finalidade de complementação da caracterização mineralógica da região em estudo. Todos os ensaios realizados, respeitaram o bioma local, visando a sua preservação. Uma variedade grande de argilominerais, bem como minerais não argilosos, quartzo, feldspato e poligorsquite, foram encontrados nas amostras. Do grupo dos argilominerais identificados, as Illitas, Caulinitas e Vermiculitas foram os argilominerais mais presente nas amostras, sendo a Illita o argilomineral que mais contribui para o comportamento do solo, pois apresenta mais que $25 \%$ do material constituinte do solo. A presença de argilominerais de baixa atividade, como Illita, Clorita, Caulinita e Mica, propicia o desenvolvimento de alta sensibilidade ao amolgamento, pois estão sujeitos à redução do limite de liquidez e da resistência amolgada sob alterações químicas no ambiente, como lixiviação e ação de agentes dispersantes.

\section{Mineralogical characterization of clays moles present in the surroundings of the natural reserve of Guaratiba: west zone of the municipality of Rio de Janeiro}

\begin{abstract}
The unbridled expansion of the large centers, as well as the lack of further studies, have led to the increasing occupation of irregular areas, as is the case today in the last mangrove areas of the Guaratiba nature reserve. The soft clay, which is very present on the Brazilian coast, always presents a challenge regarding the analysis of its behavior, since nearby areas with considerable soft clay thickness may present different geomechanical behavior. In order to better understand the behavior of soft arligas, as well as to deepen the studies in these areas of preservation, so important for the maintenance of the local biome, the present study deepens the knowledge about mineralogy of the soils of the West Zone of Rio de January. $\mathrm{X}$ - ray diffraction tests were performed at depths between $4 \mathrm{~m}$ and $6 \mathrm{~m}$, from the nine samples analyzed, as well as $x$ - ray fluorescence assays, with the purpose of complementing the mineralogical characterization of the region under study. All the tests carried out, respected the local biome, aiming at its preservation. A large variety of clay minerals, as well as non-clay minerals, quartz, feldspar and poligorsquite, were found in the samples. From the group of identified argillominerals, Illitas, Caulinitas and Vermiculitas were the most present clay minerals in the samples, with Illita being the clay mineral that contributes most to the soil behavior, since it presents more than $25 \%$ of the constituent material of the soil. The presence of low activity clay minerals, such as Illita, Chlorite, Caulinite and Mica, leads to the development of high sensitivity to grinding, as they are subject to the reduction of the liquidity limit and the resistance dented under chemical changes in the environment, such as leaching and dispersing agents.
\end{abstract}

Keywords: Mineralogy; Environmental Preservation Area; Mangrove Area; Soft Clay.

Topic: Ciências do Solo

Reviewed anonymously in the process of blind peer.
Received: 10/08/2018

Approved: 24/09/2018
Flávio Vieira da Silva Junior (10)

Instituto Militar de Engenharia, Brasil

http://lattes.cnpq.br/2211436659738090

http://orcid.org/0000-0001-7789-8670

flaviovisiju@gmail.com

Maria Esther Soares Marques (iD

Instituto Militar de Engenharia, Brasil

http://lattes.cnpq.br/8911936841113704

http://orcid.org/0000-0001-8936-2777

esther@ime.eb.br

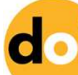

DOI: 10.6008/CBPC2179-6858.2018.007.0002
Referencing this:

SILVA JUNIOR, F. V.; MARQUES, M. E. S.. Caracterização mineralógica de argilas moles presentes nos arredores da reserva natural de Guaratiba: zona oeste do município do Rio de Janeiro. Revista Ibero Americana de Ciências Ambientais, v.9, n.7, p.12-24, 2018. DOI: http://doi.org/10.6008/CBPC2179-6858.2018.007.0002 


\section{INTRODUÇÃO}

De acordo com Mitchell (1976), a mineralogia é um fator controlador que determina a granulometria e as características superficiais das partículas do solo, assim como também determina, sua resistência e o poder de interação do solo com a fase fluida. Em conjunto, esses fatores determinam a plasticidade, a expansão, a compressão, e a condutividade da água presente no solo. Desse modo, a mineralogia é fundamental para a compreensão das propriedades geotécnicas, mesmo quando, não seja possível realizar uma quantidade muito grande de ensaios mineralógicos, pois o mesmo pode ser complementado por ensaios geotécnicos que refletem a composição e as propriedades necessárias para obras de engenharia, como é o caso dos Limites de Atterberg e Granulometria do solo. Utilizando uma analogia, podemos dizer que a mineralogia, está relacionada às propriedades do solo, assim como a forma, a composição e a estrutura do cimento e dos agregados, estão relacionadas ao concreto, ou como a composição e a estrutura cristalina de um aço, correspondem a sua resistência e deformabilidade.

Havendo necessidade de transpor as áreas de depósitos de solos moles, existem hoje diversas alternativas de projeto. Os métodos mais usuais na construção de aterros rodoviários são a remoção e substituição do solo mole, utilização de drenos verticais associados a sobrecargas, aterros leves, constituídos por isopor ou outro material, e aterros estruturados sobre estacas com plataforma flexível ou rígida. A escolha da solução dependerá de diversos fatores e para auxiliar nesta tomada de decisão é imprescindível ter o conhecimento da estratigrafia e das características e propriedades geotécnicas do solo compressível de fundação (BERBERT, 2016).

A execução de construção em locais de ocorrência de argilas moles, como é o caso de Guaratiba, localizado na Baixada de Campo Grande, zona Oeste da cidade do Rio de Janeiro, a escolha do método construtivo mais adequado está associada a diversas questões: características geotécnicas dos depósitos, materiais e técnicas disponíveis para a construção, utilização e localização da área, incluindo a vizinhança; prazos construtivos e custos envolvidos (ALMEIDA et al., 2010). Nesse contexto, o problema a ser resolvido nesse estudo, é o atual desconhecimento das características mineralógicas das argilas muito moles de Guaratiba, sendo de conhecimento acadêmico, o estudo realizado na região por Berbert (2016), pioneira nos estudos de caracterização geotécnica da região de Guaratiba, porém sem se aprofundar até a influência da caracterização mineralógica da região.

O conhecimento de parâmetros geotécnicos, para realização de expansão e ocupação de novas áreas, é fundamental, como é mostrado por Baroni (2016), em pesquisa realizada na região da baixada de Jacarepaguá, região Oeste do Município do Rio de Janeiro. Nos últimos 10 anos inúmeros eventos, como o Pan 2007 e as Olimpíadas 2016, foram realizados na região Oeste do Município do Rio de Janeiro, trazendo consigo a necessidade de expansão do transporte público para a região, a exemplo dos corredores expressos (BRT). A partir de Coutinho (1976; 2007), Futai (1997; 2002), Baroni (2010; 2016), há um grande conhecimento sobre o comportamento geomecanico das argilas da baixada de Jacarepaguá, porém os estudos mineralógicos, mesmos nessa região que muito já foi estudada, sempre foi deixada em segundo 
plano, 'um bônus'. As argilas da Baixada de Campo Grande, que do mesmo modo, se localizam na região Oeste do Município do Rio de Janeiro, apresentam características geotécnicas e geomecânicas diferentes, como mostrado por Berbert (2016).

O pouco conhecimento das características das argilas da região da Baixada de Campo Grande, onde se localiza o bairro de Guaratiba, acarretam, por vezes, na utilização de parâmetros de regiões vizinhas sem projeto, mas que acabam por não apresentarem as mesmas características geotécnicas, causando por vezes, equívocos na escolha de soluções geotécnicas. Esses equívocos causam prejuízos sociais e econômicos, onde um recalque não previsto pode causar patologias nas futuras vias, que por consequência geram prejuízos aos cofres públicos, que terá que sanar esses defeitos. Portanto existe a necessidade de aprofundar os estudos mineralógicos na região de Guraratiba, para que a compreensão quanto ao solo dessa região seja maior, e menos erros de projetos causados pelo desconhecimento das características geotécnicas da região, venham a ocorrer.

A partir do estudo realizado na Região de Guaratiba, por Berbert (2016), os ensaios de caracterização do solo permitem classificá-lo como argila orgânica de alta compressibilidade. Os estudos realizados por Baroni (2016), divergem dos resultados de compressibilidade e resistência encontrados por Berbert (2016). Tal divergência em regiões geograficamente próximas de estudos, os dois pesquisadores estudaram as argilas da região Oeste do município do Rio de Janeiro, podem ser justificadas por diferentes grupos de formação mineralógica da região. Portanto, essa pesquisa traz ao analisar, ensaios de laboratório, a caracterização física e mineralógica da região em estudo, de forma a fornecer parâmetros geotécnicos, das argilas moles da região Oeste da cidade do Rio de Janeiro.

\section{REVISÃO TEÓRICA}

\section{Argilominerais}

O termo argila, não possui necessariamente uma conotação mineralógica, sendo aplicado a todas as partículas com granulação fina encontradas em sedimentos e solos. A definição de argila, segundo a sua composição química, diz que as argilas compreendem silicatos de alumínio hidratados pertencentes aos grupos de caulinita, esmectita, illita e também clorita e vermiculita, de granulação fina.

Qualquer sedimento argiloso inicia sua história em geral, com a decomposição de feldspatos ou de outros minerais aluminossilicatados, sendo os argilominerais aluminossilicatados, os produtos finais. Alguns sedimentos clásticos, finamente divididos, como as cinzas vulcânicas e as farinhas glaciais, não apresentam a mesma história evolutiva, embora também exibam granulação muito finas. Deste modo, nem todos os sedimentos extremamente finos são compostos exclusivamente por argilominerais (SUGUIO, 2003).

Eberl (1984), afirma que existem três mecanismos de formação dos argilominerais (minerais de argila), sendo elas: Herança Detrítica ou Total - $\mathrm{O}$ argilomineral tem sua formação através de reações ocorridas em outras regiões, e posteriormente é transportado para o local atual, onde permanece inerte em seu ambiente atual; Neoformação ou Autigênese - $O$ argilomineral é formado a partir da reação do material 
Caracterização mineralógica de argilas moles presentes nos arredores da reserva natural de Guaratiba: zona oeste do município do Rio de

amorfo; Herança por Transformação - O argilomineral transportado sofre reações química. Essas reações podem ocorrer de duas maneiras, por troca de íons ou mudança na estrutura cristalina. Na mudança da estrutura cristalina, os arranjos de cátions interplanares octaédricos, tetraédricos ou fixos são modificados.

O ambiente e a energia disponível determinam quais desses mecanismos irão prevalecer na formação do argilomineral. A herança mineralógica é dominante em ambientes sedimentares, pois as temperaturas e consequentemente as taxas de reação são baixas. As transformações são comumente encontradas em ambientes hidroenergéticos diagenéticos. Os três mecanismos de formação são ativos no intemperismo, mas a herança mineralógica é mais comum em regiões de alta latitude e a neoformação é mais importante nos trópicos úmidos (MITCHELL, 1992).

De acordo com Mitchell (1992), os argilominerais são constituídos por duas unidades básicas, que se associam formando folhas e se agrupam em camadas. A distância interplanar ou espaçamento basal (d), é definido como a distância perpendicular entre essas camadas. Os diversos tipos de argilominerais existentes são resultado das diferentes ligações entre essas camadas e da substituição de íons de alumina ou sílica.

Tamanha a dificuldade de estudos microscópicos, a identificação dos argilominerais são dadas principalmente pela técnica de difração de raios-X e, em menor escala, pela análise térmica diferencial (ATD) ou outros métodos descritos na literatura. Uma definição de sequência ideal para os estudos dos argilominerais, inicia com a composição mineralógica, seguida de exame em seção delgada para se estabelecer as relações dos argilominerais com os outros minerais.

De acordo com Suguio (2003), a análise por difração de raios- $X$, é o estudo da estrutura da rede cristalina do mineral estudado, onde a clivagem basal e a estrutura em leitos fornecem os elementos necessários para que ocorra a reflexão de raios-X com espaçamento (001), principalmente em agregados mineralógicos orientados. Esses reflexos $(001,002$, etc.) podem ser facilmente reconhecidos em fotografias de diagramas de pó ou em difratogramas.

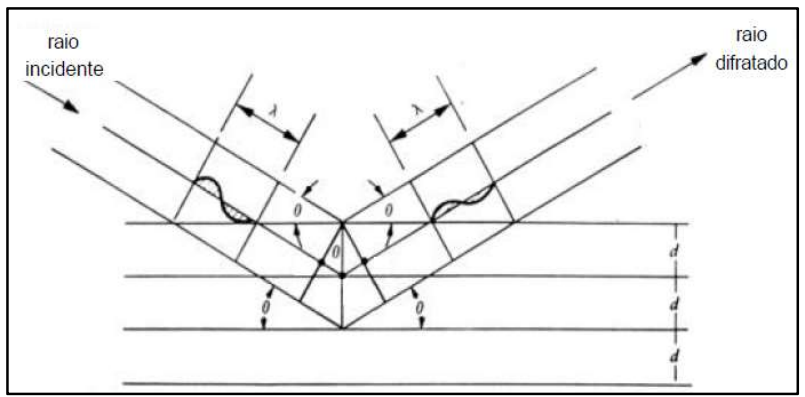

Figura 1: Condições Geométricas da Difração de Raio-X, Mitchell (1976).

Santos (1975), diz que em uma partícula de solo com estrutura cristalina, um certo conjunto de átomos é repetido em intervalos equidistantes, formando um reticulado cristalino. Define-se célula unitária como um conjunto de redes cristalinas que caracteriza o argilomineral, podendo ser entendida como a menor parte formadora do argilomineral.

Quando o solo é exposto a um feixe monocromático de raios- $\mathrm{X}$, cada célula unitária é capaz de difratar os raios-X. A frente de onda é completamente anulada, exceto nas direções em que os efeitos das 
células unitárias vizinhas provocam uma interferência construtiva completa. Somente nestas direções é que aparece um feixe difratado de raios- $X$, conforme é mostrado na Figura 1.

Através dos ensaios de difração por raios- $X$, os argilominerais podem ser classificados, dependendo da distância interplanar basal (d). O valor de d é definido como a distância entre os planos da célula unitária. O cálculo de d baseia-se na lei de Bragg, conforme mostrado por Santos (1975) através da Equação 1.

$$
\mathrm{N} \lambda=2 \mathrm{~d} \operatorname{sen} \theta
$$

Onde: $n=$ número inteiro positivo que representa a ordem de reflexão $(n=1) ; \lambda=$ comprimento de onda dos raios- $X$ (Å); $d$ = distância interplanar basal; $\theta$ = ângulo de refração.

Os ensaios de difratometria podem ser executados com lâmina natural (não glicolada), com lâminas do tipo glicolada ou ainda com lâminas aquecidas a altas temperaturas. No caso das lâminas glicoladas, é possível identificar a presença de argilominerais expansivos tal como a montmorilonita. Nas aquecidas, verifica-se o comportamento do argilomineral quando este perde sua água de constituição, reduzindo assim a distância interplanar basal. A Tabela 1 apresenta alguns exemplos de valores para classificação dos argilominerais em função da distância ' $d$ '.

Tabela 1: Distâncias interplanares basais típicas para argilominerais, Santos (1975).

\begin{tabular}{|l|l|}
\hline$d(\AA)$ & Possíveis Argilominerais \\
\hline 3,6 & Caulinita, refração secundária \\
\hline 7,1 & Caulinita, refração primária e Haloisita anidra \\
\hline 10 & Esmectita anidra, Vermiculita anidra, llita e Haloisita hidratada \\
\hline 14 & Esmectita hidratada, Vermiculita hidratada e Clorita \\
\hline 17 & Esmectita glicolada \\
\hline
\end{tabular}

O argilomineral não se restringe a um único ambiente geológico, podendo sua origem ser em diferentes ambientes de sedimentação. Todavia, em geral, a caulinita reflete condições de intensa lixiviação, pH ácido e meio muito pobre em cátions, onde essas características são comuns em ambientes fluviais de climas tropicais úmidos.

As lamas negras de origem marinha são ricas em matéria orgânica e pirita e também relativamente ricas em caulinita, assim o ambiente comumente ácido e anaeróbico de ocorrência dessas lamas, indicam condições redutoras. Os sedimentos marinhos não são muito favoráveis à ocorrência de caulinita, pois a presença de $\mathrm{Ca}^{+2}$ tende a inibir a formação deste mineral (MILLOT, 1953).

De acordo com Suguio (2003), o ambiente marinho é, em geral, alcalino e contém quantidades apreciáveis de cálcio dissolvido. Este tipo de ambiente favorece mais a formação de esmectita, da illita e da clorita, em detrimento da caulinita. Essas são também as condições mais favoráveis à formação da paligorskita (ou attapulgita), embora ela não seja exclusiva de ambientes marinhos.

Torrance (1975), ao realizar estudo químicos, físicos e mecânico, nos argilominerais marinhos, na cidade de Ottawa no Canadá, observa que a salinidade influência diretamente na sensibilidade do argilomineral, pois com o aumento da salinidade do solo, a sensibilidade também aumenta, assim como anteriormente já havia sido observado em estudos realizados na Escandinávia. 
Geertsema et al. (2005), realizam estudo de caso, onde ocorre um deslizamento de terra na Cidade de British Columbia, que movimentou 2,5 milhões de $\mathrm{m}^{3}$ de sedimento argilomineral marinho. Os estudos geotécnicos confirmam a alta sensibilidade do argilomineral. Através de estudos mineralógicos e químicos, foi possível correlacionar a sensibilidade da argila com a sua mineralogia e teor de salinidade, devido a semelhança de resultados, anteriormente encontrados no Leste do Canadá e Escandinávia. Portanto, ao desconsiderar a interação dos estudos de mineralogia e índice de plasticidade, os resultados quanto a liquefação de solos finos, têm sua confiabilidade questionada Beroya et al. (2009).

\section{Comportamento das argilas moles}

O comportamento de solos é função da distribuição granulométrica do material, bem como da mineralogia, do teor de umidade, do estado de tensões a que está submetido, etc. A porcentagem de fração argila desempenha papel fundamental na determinação das características e propriedades do solo, tais como a compressibilidade, a resistência e a permeabilidade do material. Além disso, o conhecimento das características da fração argila (argilominerais) auxilia na determinação da atividade e da suscetibilidade de ocorrência de expansão em solos moles.

Argilominerais são minerais inorgânicos de estrutura cristalina, que os elementos estruturais constituintes, os tetraedro de Si e octaedros de Al, são dispostos em camadas alternadas, que se concentram na fração argila dos solos. A influência do argilomineral nas propriedades geotécnicas do solo é medida pela atividade. A atividade das argilas depende da porcentagem de argilominerais presentes no solo. E portanto, a variação do tipo de argilomineral presente na amostra, influencia diretamente na atividade da argila mole estudada.

Skempton (1953), define índice de atividade $\left(\mathrm{l}_{\mathrm{a}}\right)$ como sendo a relação entre o índice de plasticidade e a porcentagem da fração argila (grãos com diâmetro médio inferior a $2 \mu \mathrm{m}$ ), como pode ser visto na equação 2.

$$
I_{a}=\frac{I P}{\% \leq 2 \mu m}
$$

\section{Descrição do local de estudo}

A região em estudo, está localizada na baixada de Campo Grande, localizada na Zona Oeste do município do Rio de Janeiro. A baixada de Campo Grande, localizada na zona oeste do Município do Rio de Janeiro, possui área de aproximadamente $60 \mathrm{~km}^{2}$, constituída na sua maioria por depósitos quaternários fluviomarinhos (VIEGAS, 1996).

Situada entre os Meridianos 4345'00" e 4327'03" de longitude oeste e os paralelos $22^{\circ}{ }^{\prime} 55^{\prime} 30^{\prime \prime}$ e 2300'55" de latitude sul, a baixada de Campo Grande é limitada ao norte pelo centro urbano de Campo 
Grande, ao sul pela Baía de Sepetiba, a oeste pelas Serras de Cantagalo, Inhoaíba e Capoeira Grande e a leste pelo Maciço da Pedra Branca.

Constituído basicamente por rochas cristalinas pré-cambrianas e eopaleozóicas, o Município do Rio de Janeiro é cortado por numerosos diques de rochas básicas e alcalinas do Mesozóico e Terciário. Entre os morros e as montanhas encontram-se as várzeas, as dunas e as praias, que no Município do Rio de Janeiro, são constituídos por depósitos quaternários (VIEGAS, 1996).

Constituídos por sedimentos fluviomarinhos, os depósitos quaternários, estão sobrepostos ao arcabouço pré-cambriano formando a baixada de Campo Grande (VIEGAS, 1996). De acordo com o descrito por Ponçano et. al. (1976), da base para o topo da coluna sedimentar, existe uma passagem de sedimentos de origem continental para sedimentos de origem mista, continental e marinha, o que caracteriza uma sequência transgressiva.

Durante o Quaternário, a área em estudo, foi severamente afetada pelas últimas transgressões e regressões que deixaram evidências através dos depósitos sedimentares (VIEGAS, 1996). O nível do mar, nos últimos seis mil anos, esteve superior ao atual em pelo menos duas ocasiões: uma transgressão entre 5400 e 4600 anos, com o nível do mar chegando a 4,5 metros acima do atual e outra entre 3500 e 3200 anos com o nível do mar chegando a 3,0 metros acima do atual. Nos últimos 1800 anos, a posição atual do nível do mar foi atingida (FERREIRA et al., 1988)

Pode-se dividir a área sedimentar da região em estudo em duas, onde a primeira é composta por espessas camadas de argila orgânica, que podem chegar a mais de 10 metros, sobrepostas a camadas argilosiltosas e camadas arenosas que podem conter fragmentos de conchas, o que evidencia a presença do mar durante as várias transgressões e regressões ocorridas durante o quaternário. A segunda região, com ocorrência principalmente na parte central e norte da região em estudo, é composta principalmente por sedimentos de origem fluvial, caracterizados por uma pequena espessura, no máximo de 10 metros. Bastante heterogêneo, o material varia em composição de argilas-siltosas a areias-argilosas finas, médias e grossas, podendo chegar a conter um pequeno percentual de argila e silte (VIEGAS, 1996).

O local de estudo foi dividido em Zona 1 e Zona 2, onde foram realizadas 15 Ilhas de investigação geotécnica. Foram realizadas 98 sondagens, retirada de 31 amostras indeformadas com Tubo Shelby, 78 ensaios de palheta (Vane Test) e 17 ensaios de piezocone (CPTu). Foram realizados em laboratório 76 ensaios de caracterização física completa, 29 ensaios de adensamento oedométrico, 9 ensaios de difração de Raios$X$ e 5 ensaios de Fluorescência de Raios-X.

A Figura 2, é a representação do local de estudo, dentro do contexto da região, demonstrando a importância do estudo na região. A Figura 3 é composta pela representação das isoespessuras do local em estudo. A Figura 4, é a representação de uma seç̧ão transversal realizada na Zona 1 em estudo que demonstra a divisão das camadas. 


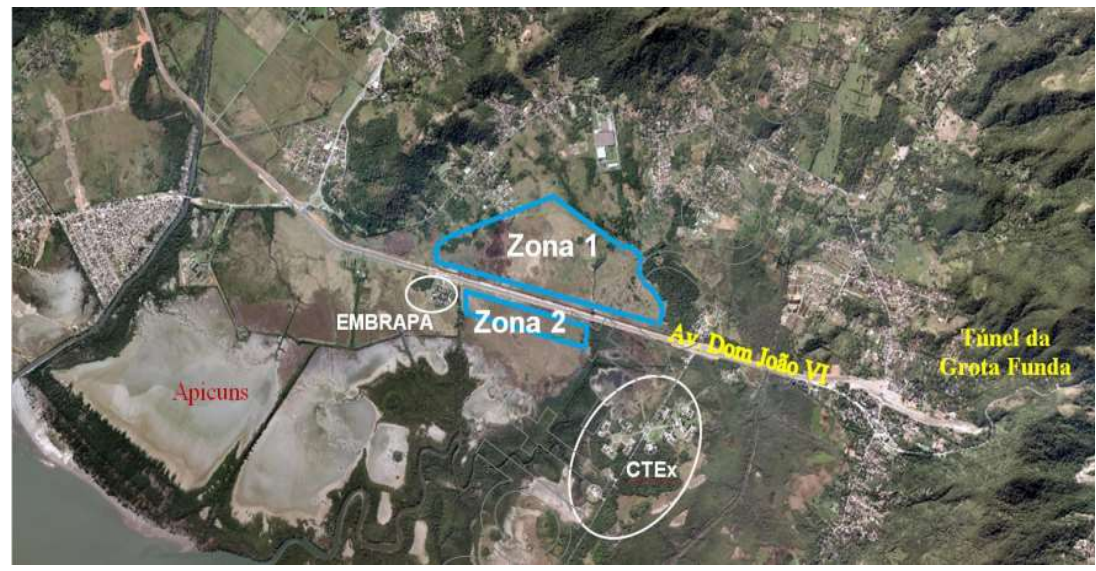

Figura 2: Representação da divisão da área de estudos.

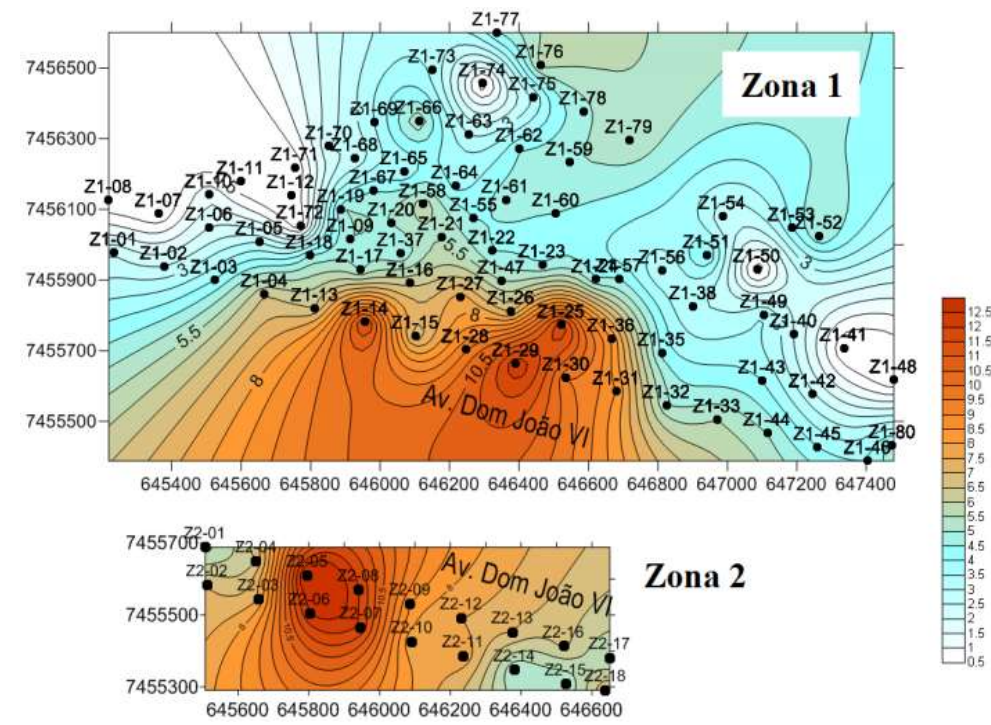

Figura 3: Isoespessuras - Zona 1 e Zona 2.

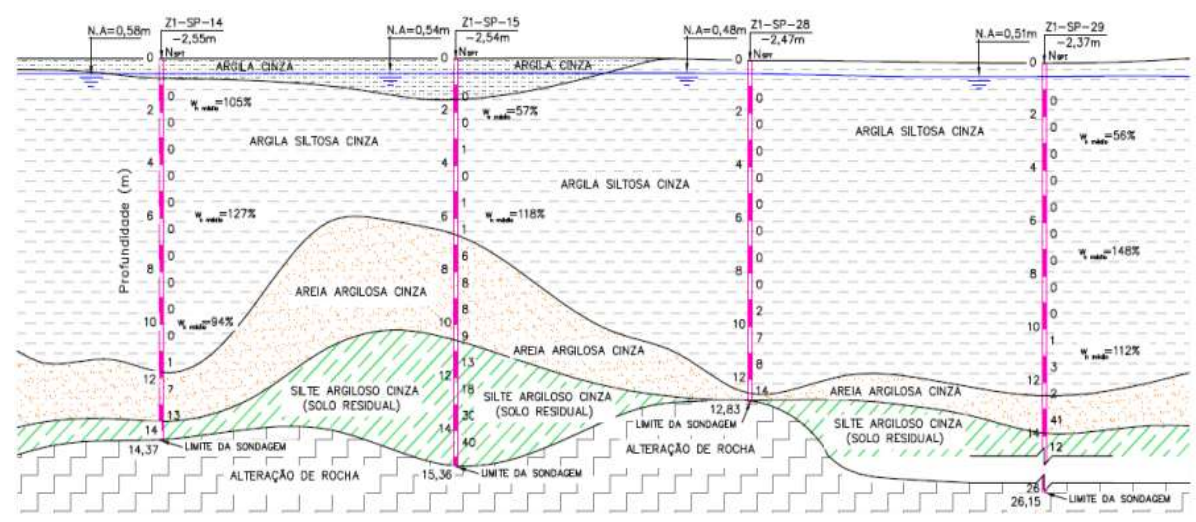

Figura 4: Seção Transversal - Espessuras das camadas de argila.

O mapa de isoespessura da Zona 1, mostra espessuras de argilas variando de pequenas espessuras, próximas de 0 metros, até grandes profundidades de 12,5 metros. A Zona 2, mais ao Sul da região estudada, contém espessuras de argilas variando de 4 metros a 14 metros. Tais espessuras evidenciam que regiões mais próximas da região costeira, mais ao sul da baixada de Campo Grande, possui maiores espessuras de solo orgânico residual. 
Caracterização mineralógica de argilas moles presentes nos arredores da reserva natural de Guaratiba: zona oeste do município do Rio de Janeiro

\section{RESULTADOS}

A coleta de solo, bem como todos os ensaios de campo, foram realizada seguindo todos os procedimentos, descritos por Schnaid et al. (2012), em seu livro denominado 'Ensaios de Campo e Suas Aplicações à Engenharia de Fundações', e as normas brasileiras regulamentadoras vigentes.

\section{Caracterização física do solo}

Foram realizados ensaios de granulometria, limites de Atterberg, densidade, teor de matéria orgânica e adensamento oedométrico com a finalidade de caracterizar fisicamente o solo estudado. As Tabelas 2 e 3, mostram os resultados obtidos através desses ensaios.

Tabela 2: Resultados de Caracterização Física do Solo.

\begin{tabular}{|c|c|c|c|c|c|c|c|c|c|c|c|c|c|}
\hline \multirow{2}{*}{ Amostra } & \multirow{2}{*}{ wh (\%) } & \multirow{2}{*}{$\gamma \operatorname{rax}\left(\mathrm{kN} / \mathrm{m}^{3}\right)$} & \multicolumn{3}{|c|}{ Granulo metria } & \multicolumn{3}{|c|}{ Limites de Atterberg } & \multirow{2}{*}{ IA } & \multirow{2}{*}{ Gs } & \multirow{2}{*}{ TMO $(\%)$} & \multirow{2}{*}{ s } & \multirow{2}{*}{$\mathrm{e}_{0}$} \\
\hline & & & $\%$ Areia & $\%$ Silte & $\%$ Argila & LL $(\%)$ & LP (\%) & IP (\%) & & & & & \\
\hline Z1-SP-04-3m & 108,60 & 13,70 & 5,90 & 57,30 & 36,80 & 93 & 49 & 44 & 1,20 & 2,608 & 4,56 & 97,88 & 2,890 \\
\hline $\mathrm{Z} 1-\mathrm{SP}-04-5 \mathrm{~m}$ & 40,10 & 17,60 & 6,90 & 60,00 & 33,10 & 90 & 45 & 45 & 1,36 & 2,617 & 1,74 & 100,34 & 1,043 \\
\hline Z1-SP-14-2m & 111,60 & 13,60 & 3,00 & 60,20 & 36,80 & 93 & 52 & 41 & 1,11 & 2,624 & 13,34 & 97,02 & 3,020 \\
\hline Z1-SP-14-6m & 130,00 & 13,60 & 11,70 & 56,50 & 31,90 & 91 & 43 & 48 & 1,50 & 2,622 & 6,84 & 100,00 & 3,340 \\
\hline Z1-SP-14-8m & 130,50 & 13,40 & 4,90 & 60,90 & 34,30 & 92 & 51 & 41 & 1,20 & 2,628 & 8,59 & 99,73 & 3,440 \\
\hline Z1-SP-18-1,5m & 75,20 & 15,30 & 18,10 & 56,50 & 25,40 & 89 & 49 & 40 & 1,57 & 2,601 & 4,56 & 100,00 & 1,920 \\
\hline Z1-SP-18-3,5m & 118,70 & 13,60 & 12,40 & 57,60 & 30,00 & 92 & 47 & 45 & 1,50 & 2,669 & 5,30 & 98,95 & 3,200 \\
\hline Z1-SP-20-3m & 115,90 & 13,70 & 6,70 & 44,90 & 48,40 & 94 & 52 & 42 & 0,87 & 2,619 & 3,40 & 99,46 & 3,050 \\
\hline Z1-SP-27-3m & 113,20 & 13,80 & 9,00 & 44,90 & 46,10 & 95 & 52 & 43 & 0,93 & 2,634 & 3,77 & 99,90 & 2,980 \\
\hline Z1-SP $-27-5 \mathrm{~m}$ & 125,30 & 13,40 & 12,90 & 42,40 & 44,70 & 90 & 51 & 39 & 0,87 & 2,617 & 6,45 & 99,18 & 3,300 \\
\hline Z1-SP-27-7m & 129,40 & 13,10 & 9,30 & 49,20 & 41,60 & 92 & 50 & 42 & 1,01 & 2,603 & 7,91 & 97,01 & 3,460 \\
\hline Z1-SP-29-2m & 71,70 & 15,50 & 4,70 & 50,30 & 44,70 & 94 & 51 & 43 & 0,96 & 2,614 & 3,66 & 100,00 & 1,830 \\
\hline Z1-SP-29-6m & 147,30 & 13,00 & 14,50 & 44,90 & 40,50 & 89 & 49 & 40 & 0,99 & 2,621 & 4,84 & 99,68 & 3,870 \\
\hline Z1-SP-29-10m & 139,10 & 13,00 & 14,50 & 48,00 & 37,50 & 87 & 48 & 39 & 1,04 & 2,629 & 3,66 & 97,72 & 3,740 \\
\hline Z1-SP-33-2m & 73,00 & 15,20 & 7,20 & 42,50 & 50,30 & 90 & 51 & 39 & 0,78 & 2,611 & 2,60 & 99,43 & 1,920 \\
\hline Z1-SP-33-5m & 122,00 & 13,40 & 4,70 & 54,70 & 40,60 & 78 & 46 & 32 & 0,79 & 2,603 & 8,53 & 98,35 & 3,230 \\
\hline $\mathrm{Z} 1-\mathrm{SP}-36-3 \mathrm{~m}$ & 132,80 & 13,30 & 9,00 & 50,40 & 40,60 & 90 & 49 & 41 & 1,01 & 2,623 & 7,94 & 99,42 & 3,500 \\
\hline Z1-SP-36-7m & 132,00 & 13,30 & 9,90 & 49,70 & 40,40 & 92 & 48 & 44 & 1,09 & 2,620 & 4,99 & 99,61 & 3,470 \\
\hline Z1-SP-50-2m & 78,40 & 14,60 & 24,70 & 47,40 & 27,90 & 82 & 44 & 38 & 1,36 & 2,616 & 2,89 & 96,33 & 2,130 \\
\hline Z1-SP - $60-4 \mathrm{~m}$ & 118,10 & 13,50 & 17,10 & 52,90 & 30,10 & 85 & 46 & 39 & 1,30 & 2,595 & 3,98 & 98,81 & 3,095 \\
\hline Z1-SP-66-3m & 68,30 & 14,70 & 17,70 & 52,30 & 30,00 & 88 & 49 & 39 & 1,30 & 2,663 & 3,16 & 91,38 & 1,987 \\
\hline Z1-SP-76-3m & 122,40 & 13,50 & 13,70 & 51,90 & 34,40 & 91 & 49 & 42 & 1,22 & 2,628 & 6,78 & 99,32 & 3,230 \\
\hline Z1-SP-76-5m & 74,70 & 15,00 & 17,50 & 43,70 & 38,90 & 85 & 47 & 38 & 0,98 & 2,613 & 9,89 & 98,64 & 1,980 \\
\hline Z2-SP-06-4m & 144,80 & 13,07 & - & 75,40 & 24,60 & 81 & 52 & 29 & 1,18 & 2,566 & 4,30 & 100,00 & 3,711 \\
\hline $\mathrm{Z} 2-\mathrm{SP}-06-7 \mathrm{~m}$ & 119,20 & 13,43 & 37,40 & 30,60 & 32,00 & 86 & 52 & 34 & 1,06 & 2,485 & 6,50 & 99,00 & 2,978 \\
\hline ZZ-SP-06-10m & 110,50 & 13,37 & 33,90 & 35,80 & 30,40 & 88 & 50 & 38 & 1,25 & 2,451 & 6,80 & 97,00 & 2,786 \\
\hline Z2-SP-09-5m & 113,30 & 13,70 & 19,90 & 46,00 & 34,10 & 93 & 52 & 41 & 1,20 & 2,537 & 6,20 & 100,00 & 2,873 \\
\hline Z2-SP-09-7m & 110,40 & 13,65 & 19,70 & 45,50 & 34,70 & 95 & 55 & 40 & 1,15 & 2,437 & 7,50 & 100,00 & 2,685 \\
\hline Z2-SP - $14-2 m$ & 111,30 & 13,15 & 32,40 & 39,80 & 27,80 & 83 & 41 & 42 & 1,51 & 2,591 & 4,90 & 93,00 & 3,085 \\
\hline Z2-SP-14-4m & 112,40 & 13,77 & 30,80 & 42,60 & 26,60 & 80 & 41 & 39 & 1,47 & 2,536 & 5,40 & 100,00 & 2,838 \\
\hline
\end{tabular}

A Zona 2, apesar de apresentar maiores espessuras de argila, como visto na Figura 3, desse trabalho, não apresenta espessura de matéria orgânica representativa, que justificasse a realização do ensaio de teor de matéria orgânica. As ilhas de investigação foram locadas após a realização das sondagens, onde a partir do caracterizado pela sondagem, foi possível verificar quais eram as piores verticais, e assim realizar a retirada de amostras indeformadas, bem como a realização dos ensaios de campo necessários, nos locais que apresentaram as piores situações geotécnicas (maiores camadas de argila). 
Caracterização mineralógica de argilas moles presentes nos arredores da reserva natural de Guaratiba: zona oeste do município do Rio de Janeiro

Tabela 3: Resultados dos Parâmetros de Compressibilidade.

\begin{tabular}{|c|c|c|c|c|c|c|c|c|c|c|c|c|c|}
\hline Amostra & Prof.(m) & NA $(m)$ & $\sigma v_{0}(\mathrm{kPa})$ & $\sigma \times m(k P a)$ & OCR & $\mathrm{e}_{0}$ & evo & $\mathrm{Cr}$ & $\mathrm{Cc}$ & $\begin{array}{c}C R= \\
C d\left(1+e_{0}\right)\end{array}$ & $\varepsilon s e c$ & $\begin{array}{c}\text { Cv (Taylor) } \\
\left(10^{8} \mathrm{x} \mathrm{m}^{2} / \mathrm{s}\right)\end{array}$ & $\begin{array}{c}\text { Or (Casagrande) } \\
\left(10^{-8} \times \mathrm{m}^{2} / \mathrm{s}\right)\end{array}$ \\
\hline \multirow{3}{*}{$\mathrm{Z} 2-\mathrm{SP}-06$} & $4, \infty$ & 0,61 & 18,38 & $7, \infty$ & 0,38 & 3,711 & NP & NP & NP & $\mathrm{NP}$ & NP & 1,32 & - \\
\hline & $7, \infty$ & 0,61 & 28,13 & 22,00 & 0,78 & 2,978 & 2,530 & 0,13 & 1,76 & 0,44 & 12,396 & 1,40 & - \\
\hline & $10, \infty$ & 0,61 & 38,33 & 32,00 & 0,83 & 2,786 & 2,420 & 0,09 & 1,61 & 0,43 & 12,196 & 1,90 & - \\
\hline \multirow{2}{*}{$\mathrm{Z2}-\mathrm{SP}-09$} & $5, \infty$ & 1,27 & 31,20 & 28,00 & 0,90 & 2,873 & 2,460 & 0,20 & 1,53 & 0,40 & 10,396 & 1,40 & - \\
\hline & $7, \infty$ & 1,27 & 38,55 & 38,00 & 0,99 & 2,685 & 2,430 & 0,11 & 1,57 & 0,43 & 11,996 & 1,90 & - \\
\hline \multirow{2}{*}{$\mathrm{Z} 2-\mathrm{SP}-14$} & $2, \infty$ & 0,81 & 14,40 & 27,00 & 1,88 & 3,085 & 2,960 & 0,10 & 1,76 & 0,43 & 12,296 & 1,30 & - \\
\hline & $4, \infty$ & 0,81 & 21,32 & 25,00 & 1,17 & 2,838 & 2,650 & 0,13 & 1,50 & 0,39 & 10,796 & 1,40 & - \\
\hline \multirow{2}{*}{$\mathrm{Z} 1-\mathrm{SP}-36$} & $3, \infty$ & $0, \infty$ & 10,77 & 36,00 & 3,34 & 3,488 & 3,430 & 0,11 & 1,93 & 0,43 & 12,096 & 1,44 & 1,15 \\
\hline & $7, \infty$ & $0, \infty$ & 25,13 & 35,00 & 1,39 & 3,470 & 3,290 & 0,11 & 1,96 & 0,44 & 12,396 & 1,92 & 1,47 \\
\hline \multirow{3}{*}{$\mathrm{Z} 1-\mathrm{SP}-27$} & $3, \infty$ & 0,80 & 20,24 & 42,00 & 2,08 & 2,975 & 2,880 & 0,14 & 1,63 & 0,41 & 11,496 & 1,90 & 1,35 \\
\hline & $5, \infty$ & 0,80 & 28,01 & 30,00 & 1,07 & 3,292 & 3,080 & 0,17 & 1,64 & 0,38 & 10,686 & 1,28 & 1,10 \\
\hline & $7, \infty$ & 0,80 & 35,05 & 43,00 & 1,23 & 3,457 & 3,300 & 0,10 & 1,83 & 0,41 & 11,596 & 3,02 & 1,68 \\
\hline \multirow{2}{*}{$\mathrm{Z} 1-\mathrm{SP}-18$} & 1,50 & $1, \infty$ & 18,42 & 50,00 & 2,71 & 1,920 & 1,870 & 0,08 & 0,85 & 0,29 & 8,196 & 8,39 & NP \\
\hline & 3.5 & $1, \infty$ & 23,62 & 45,00 & 1,91 & 3,187 & 3,080 & 0,09 & 1,76 & 0,42 & 11,896 & 2,66 & 1,38 \\
\hline $\mathrm{Z1}-\mathrm{SP}-60$ & $4, \infty$ & $1, \infty$ & 25,16 & 45,00 & 1,79 & 3,088 & 2,980 & 0,07 & 1,56 & 0,38 & $10,5 \% 6$ & 4,72 & 2,49 \\
\hline \multirow{3}{*}{$\mathrm{Z} 1-\mathrm{SP}-29$} & $2, \infty$ & 0,51 & 16,76 & 38,00 & 2,27 & 1,830 & 1,740 & 0,13 & 0,78 & 0,28 & 7,896 & 2,86 & 2,10 \\
\hline & $6, \infty$ & 0,51 & 29,96 & 31,00 & 1,03 & 3,870 & 3,640 & 0,17 & 2,16 & 0,44 & 12,496 & 1,55 & 1,51 \\
\hline & 10,00 & 0,51 & 43,06 & 33,00 & 0,77 & 3,740 & 3,280 & 0,14 & 1,99 & 0,42 & 11,896 & 1,76 & - \\
\hline \multirow{2}{*}{$\mathrm{Z} 1-\mathrm{SP}-33$} & $2, \infty$ & $1, \infty$ & 20,98 & 23,00 & 1,10 & 1,920 & 1,780 & 0,10 & 0,78 & 0,27 & $7,5 \% 6$ & 3,11 & - \\
\hline & $5, \infty$ & $1, \infty$ & 34,72 & 30,00 & 0,86 & 3,230 & 2,900 & 0,16 & 1,56 & 0,37 & 10,196 & 1,33 & - \\
\hline$Z 1-S P-20$ & $3, \infty$ & 0,94 & 21,25 & 6,50 & 0,31 & 2,910 & 2,450 & 0,33 & 0,96 & 0,25 & 6,896 & 2,47 & - \\
\hline$Z 1-S P-50$ & $2, \infty$ & 0,73 & 17,14 & 34,00 & 1,98 & 2,130 & 2,030 & 0,12 & 0,95 & 0,30 & $8,5 \% 6$ & 4,11 & - \\
\hline$Z 1-S P-66$ & $3, \infty$ & 1,20 & 26,94 & $40, \infty 0$ & 1,48 & 1,990 & 1,870 & 0,09 & 0,93 & 0,31 & 8,796 & 2,14 & - \\
\hline \multirow{2}{*}{$Z 1-S P-76$} & $3, \infty$ & 1,10 & 22,34 & $\mathrm{NP}$ & $\mathrm{NP}$ & 3,230 & 2,780 & NP & 0,89 & 0,21 & 5,676 & 1,37 & - \\
\hline & $5, \infty$ & 1,10 & 31,45 & 49,00 & 1,56 & 1,980 & 1,850 & 0,12 & 0,90 & 0,30 & 8,496 & 1,76 & - \\
\hline \multirow{3}{*}{$\mathrm{Z} 1-\mathrm{SP}-14$} & $2, \infty$ & 0,58 & 12,88 & $32, \infty$ & 2,48 & 3,020 & 2,950 & 0,12 & 1,60 & 0,40 & 11,086 & 2,85 & - \\
\hline & $6, \infty$ & 0,58 & 27,14 & 50,00 & 1,84 & 3,340 & 3,210 & 0,15 & 2,19 & 0,50 & 14,396 & 1,17 & - \\
\hline & $8, \infty$ & 0,58 & 34,11 & 48,00 & 1,41 & 3,440 & 3,300 & 0,11 & 2,06 & 0,46 & 13,096 & 1,22 & - \\
\hline \multirow{2}{*}{$\mathrm{Z} 1-\mathrm{SP}-04$} & $3, \infty$ & 0,66 & 17,67 & 43,00 & 2,43 & 2,890 & 2,800 & 0,15 & 1,51 & 0,39 & 11,096 & 2,90 & - \\
\hline & $5, \infty$ & 0,66 & 28,91 & $\mathrm{NP}$ & NP & 1,040 & 0,930 & NP & 0,23 & 0,11 & 3,296 & 69,40 & - \\
\hline
\end{tabular}

O índice de plasticidades das verticais estudadas não demonstraram grandes variações, menores que $20 \%$, com todos os valores variando entre $30 \%$ e $50 \%$. O coeficiente de adensamento vertical, mostra ser o parâmetro mais afetado, entre as verticais, pois em alguns casos chega a ser quase 8 vezes maior, por exemplo quando comparamos as verticais 14 e 18. Dessa forma, é possível então estar afirmando que o solo da região se comporta como um solo orgânico de alta compressibilidade.

\section{Caracterização mineralógica do solo}

A fim de determinar a mineralogia presente nas argilas moles estudadas, foi realizado o ensaio de difração de raio-x. As amostras foram preparadas com amostras de solo passante na peneira \#200 $(0,074 \mathrm{~mm})$ dispersada em água destilada. Com o uso de uma pipeta, foi separada uma porção desta dispersão e o material foi gotejado sobre a lâmina, que após isso permaneceu secando por 24 horas em um dessecador. Maiores detalhes sobre a teoria que embasa os procedimentos e os resultados obtidos através do ensaio de difração de raio-x, são descritos por Santos (1975), Mitchell (1975) e também nos capítulos anteriores desse trabalho. Os resultados encontrados a partir do ensaio de difração de raio-x são apresentados a seguir no Quadro 1.

Por se tratar de uma região com ocorrência de grandes espessuras de argila mole, esperava-se que no ensaio de difração de raio-x, fossem encontrados apenas argilominerais. Como pode ser visto nos resultados dos ensaios, minerais com comportamentos e tamanho diferentes dos argilominerais foram detectados, como Quartzo, Feldspato e Paligorsquite, que também constituem o solo dessa região. 
Caracterização mineralógica de argilas moles presentes nos arredores da reserva natural de Guaratiba: zona oeste do município do Rio de

Quadro 1: Minerais Encontrados na Zona 1 - Vertical 15-4m.

\begin{tabular}{|c|c|c|c|c|c|c|c|c|}
\hline \multicolumn{7}{|c|}{ Identificação Visual dos Minerais Através do Ensaio de Difração de Raios - X } \\
\hline \multicolumn{2}{|c|}{ Identificação } & Profundidade $(\mathrm{m})$ & \multicolumn{7}{c|}{ Minerais } \\
\hline \multirow{5}{*}{ Zona 1 } & Vertical 15 & 4 & Illita & Mica & Halloysita & Feldspato & Clorita & Vermiculita \\
\cline { 2 - 9 } & Vertical 23 & 4 & Carboneto & Clorita & Caulinita & - & - & - \\
\cline { 2 - 9 } & Vertical 55 & 4 & Caulinita & Quartzo & Illita & Clorita & Vermiculita & Clorita \\
\cline { 2 - 9 } & Vertical 60 & 5 & Quartzo & Illita & Paligorsquite & - & - & - \\
\cline { 2 - 9 } & Vertical 64 & 5 & Quartzo & Illita & Clorita & - & - & - \\
\cline { 2 - 9 } & Vertical 76 & 5 & Vermiculita & Feldspato & Caulinita & Paligorsquite & - & - \\
\hline \multirow{3}{*}{ Zona 2 } & \multirow{3}{*}{ Vertical 16 } & 4 & Quartzo & Illita & Clorita & Caulinita & Vermiculita & - \\
\cline { 3 - 9 } & & 5 & Quartzo & Illita & Paligorsquite & Mica & Vermiculita & Clorita \\
\cline { 2 - 9 } & & 6 & Quartzo & Illita & Feldspato & Mica & Vermiculita & Clorita \\
\hline
\end{tabular}

Em estudo realizado na baixada de Jacarépagua, Tassi (2015), também encontrou partículas de Quartzo ao realizar ensaio de difração de raio-x. Tais partículas podem ser fragmentos do fim do terciário, onde se desprenderam dos montes que se encontram nas proximidades, e foram transportadas para o local de estudo, onde encontra-se até hoje. Outra possibilidade que justificaria tais partículas nessa região, seria a ocorrência de lentes de material arenoso, próximo aos locais de retirada de material para o ensaio. Através das análises de cada uma das verticais, é possível notar que os minerais que diferem dos argilominerais, são mais presentes quão mais chegamos próximo ao oceano, pois se tornam mais evidentes na Zona 2, que fica mais próxima do oceano, enquanto a Zona 1, fica mais próxima dos morros da região.

A classificação do solo através da caracterização física, o classifica como uma argila ôrganica, porém ao realizar o ensaio de difração de raio-x e constatar que há partículas que apresentam características distintas dos argilominerais, é provável que locais com ocorrência de argila siltosa, estejam presentes no local de estudo. A ocorrência de argilominerais do grupo da Illita e da Caulinita, que são minerais de menor atividade, justificam o baixo indice de plasticidade encontrados nas amostras estudadas.

\section{Caracterização química do solo}

A análise da composição química dos grãos do solo se deu pelo método físico, por meio de fluorescência de Raios - X (FRX), que é uma análise química total, que quantifica os componentes dos minerais primários e secundários. Por meio das análises semiquantitaticas de Fluorescência de Raios-X (FRX), foi possível conhecer as concentrações, em porcentagem, dos óxidos presentes na amostra, principalmente de $\mathrm{SiO}_{2}, \mathrm{Al}_{2} \mathrm{O}_{3}, \mathrm{Fe}_{2} \mathrm{O}_{3}, \mathrm{TiO}_{3}, \mathrm{MgO}, \mathrm{CaO}, \mathrm{K}_{2} \mathrm{O}, \mathrm{Na}_{2} \mathrm{O}$ e $\mathrm{SO}_{3}$, como pode ser visto na Tabela 4. As análises conseguiram captar mais que $99,4 \%$ dos componentes presentes no solo.

Tabela 4: Resultado da Composição Química Total dos Grãos por Fluorescência de Raios - X.

\begin{tabular}{|c|c|c|c|c|c|c|c|c|c|c|c|c|c|c|c|c|c|}
\hline \multirow{2}{*}{ Amostras } & \multicolumn{17}{|c|}{ Fluorescincla de Ralos - $\mathrm{X}(\%)$} \\
\hline & $\mathrm{SIO}_{2}$ & $\mathrm{Fe}_{2} \mathrm{O}_{3}$ & $\mathrm{Al}_{2} \mathrm{O}_{3}$ & $\mathrm{~K}_{2} \mathrm{O}$ & $\mathrm{TIO}_{2}$ & $\mathrm{CaO}$ & $\mathrm{SO}_{3}$ & $\mathrm{Cl}_{2} \mathrm{O}_{3}$ & $\mathrm{ZrO}_{2}$ & $\mathrm{P}_{2} \mathrm{O}_{\mathrm{S}}$ & $\mathrm{MgO}$ & sro & $\mathrm{Na}_{2} \mathrm{O}$ & $\mathrm{BaO}$ & Mno & $\mathrm{Eu}_{2} \mathrm{O}_{3}$ & $50 \mathrm{ma}(\%)$ \\
\hline$z 1-5 P-15-6,5 m$ & 26,670 & 42,989 & 19,905 & 0,459 & 3,317 & 0,432 & 0,222 & 2,267 & 0,429 & 0,902 & 0,170 & 0,634 & 0,177 & 0,832 & - & - & 99,41 \\
\hline $\mathrm{Z1}-5 \mathrm{P}-55-4 \mathrm{~m}$ & 39,829 & 26,234 & 15,593 & 5,445 & 3,070 & 3,168 & 3,606 & 0,865 & 0,617 & 0,539 & 0,548 & 0,113 & 0,144 & - & 0,167 & - & 99,94 \\
\hline$Z 1-5 p-60-5 m$ & 41,918 & 24,423 & 11,950 & 7,642 & 3,141 & 4,957 & 0,749 & 1,731 & 0,944 & 0,570 & 0,771 & 0,148 & 0,310 & - & 0,135 & Q,118 & 99,51 \\
\hline $21-5 p-64-5 m$ & 40,655 & 25,909 & 13,409 & 6,324 & 2,827 & 2,760 & 4,328 & 0,831 & 0,573 & 0,558 & 0,577 & 0,156 & 0,199 & - & 0,254 & 0,102 & 99,46 \\
\hline $22-5 p-16-6 m$ & 52,836 & 15,105 & 10,862 & 9,873 & 2,715 & 2,136 & 0,909 & 2,647 & 0,612 & 0,599 & 0,767 & 0,108 & 0,374 & - & - & - & 99,54 \\
\hline
\end{tabular}

De acordo com o exposto, é possível afirmar, baseado nos resultados de sílica $\left(\mathrm{SiO}_{2}\right)$ e óxidos de ferro $\left(\mathrm{Fe}_{2} \mathrm{O}_{3}\right)$, em conjunto com o apresentado nos resultados de análise por difração de raios-x, que o principal 
Caracterização mineralógica de argilas moles presentes nos arredores da reserva natural de Guaratiba: zona oeste do município do Rio de

argilomineral, na composição dos depósitos estudados é a llita, estimada em 25 a 30\%. Divergindo do encontrado por Lima e Campos (2014) em depósito localizado em Guaratiba - RJ, próximo do local em estudo, onde foi detectado como principal argilomineral a Caulinita, com traços secundários de Illita e outros argilominerais. Tais resultados corroboram para a afirmação de heterogeneidade dos solos da Zona Oeste do Rio de Janeiro.

\section{CONCLUSÕES}

Com a necessidade de expansão dos grandes centros urbanos, transpor áreas de complexa estrutura geotécnica e ambiental, se torna cada vez mais usual. Para tanto, a necessidade de conhecimento aprofundado sobre a geotecnia e o comportamento dos solos é indispensável, bem como a consideração com os devidos cuidados ambientais necessários de preservação do bioma.

A argila mole, muito presente na costa brasileira, sempre proporciona um desafio, quanto a análise do seu comportamento, pois áreas próximas e com presença de espessuras consideráveis de argila mole, podem apresentar comportamentos distintos. Com a finalidade de contribuir para melhor compreensão do comportamento das argilas moles da zona oeste do Rio de Janeiro, o presente estudo aprofundou o conhecimento sobre a mineralogia dessa região. Expondo a importância dos estudos mineralógicos para a melhor compreensão do comportamento e características das argilas moles.

Os ensaios de difração de raio-x com a finalidade de conhecer a mineralogia das amostras, foram realizados em profundidades entre $4 \mathrm{~m}$ e $6 \mathrm{~m}$, a fim de manter homogeneidade das amostras. Mesmo com profundidades próximas, e obtenção das amostras de uma mesma região, uma variedade grande de argilominerais, bem como minerais de comportamento siltosos e arenosos, foram encontrados nas amostras.

O índice de plasticidade, é um índice físico, que é diretamente influenciado pela mineralogia do solo. Nesse estudo, não se constatou uma relevante mudança no índice de plasticidade das amostras, mesmo com a grande variedade de minerais presentes nas amostras estudadas, pois o índice de plasticidade das amostras mostraram pouca variação, ficando entre $29 \%$ e $48 \%$, todas as amostras analisadas.

Do grupo dos argilominerais identificados, as Illitas, Caulinitas e Vermiculitas foram os argilominerais mais presente nas amostras, sendo a Illita o argilomineral que mais contribui para o comportamento do solo, pois apresenta mais que $25 \%$ do material constituinte do solo. A presença de argilominerais de baixa atividade, como Illita, Clorita, Caulinita e Mica, propicia o desenvolvimento de alta sensibilidade ao amolgamento, pois estão sujeitos à redução do limite de liquidez e da resistência amolgada sob alterações químicas no ambiente, como lixiviação e ação de agentes dispersantes.

\section{REFERÊNCIAS}

ALMEIDA, M. S. S. e MARQUES, M. E. S.. Aterros sobre solos moles: projeto e desempenho. São Paulo: Oficina de Textos, 2010.

AMARAL, C. P.. Mapeamento geológico-geotécnico da baixada de Sepetiba e maciços circunvizinhos: parte sul da folha de Santa Cruz. Tese (Mestrado em Geologia) Universidade Federal do Rio de Janeiro, Rio de Janeiro, 1988.

BARONI, M.. Comportamento geotécnico de argilas extremamente moles da baixada de Jacarepaguá, RJ. Tese 
(Doutorado) - Universidade Federal do Rio de Janeiro, Rio de Janeiro 2016.

BARONI, M.. Investigação geotécnica em argilas orgânicas muito compressíveis em depósitos da Barra da Tijuca. Dissertação (Mestrado) - Universidade Federal do Rio de Janeiro, Rio de Janeiro, 2010.

BERBERT, L.. Avaliação do coeficiente de adensamento vertical e horizontal de um depósito de solo mole para a previsão de recalques em obras de infraestrutura. Dissertação (Mestrado) - Instituto Militar de Engenharia, Rio de Janeiro, 2016.

BEROYA, M. A. A.; AYDIN, A.; KATZENBACH, R.. Insight into the effects of clay mineralogy on the cyclic behavior of siltclay mixtures. Enginnering Geology, v.106, p.154-162, 2009.

COUTINHO, R. Q.. Características de adensamento com drenagem radial de uma argila mole da Baixada Fluminense. Dissertação (Mestrado) - Universidade Federal do Rio de Janeiro, Rio de Janeiro, 1976.

COUTINHO, R. Q.. Characterization and engineering properties of recife soft clays - Brazil. In: Characterization and Engineering Properties of Natural Soils. Taylor and Francis \pm Balkema, 2007. p.2049-2100.

EBERL, D. D.. Clay mineral formation and transformation in rocks and soils. Philosophical transactions of the royal society of London, v.311, n.1517, p.241-257, 1984.

FERREIRA, A. M. M.; OLIVEIRA, M. V.. Contribuição ao estudo Arqueo-Geológico do Quaternário superior da baixada de Guaratiba-Sepetiba. In: Coletores e pescadores préhistóricos de Guaratiba - Rio de Janeiro. Rio de Janeiro: UFRJ; Niterói: UFF, 1988, p.31-46.

FUTAI, M. M.. Análise de Ensaios Edométricos com sucção Controlada em Solos Colapsíveis. Dissertação (Mestrado) Universidade Federal do Rio de Janeiro, Rio de Janeiro, 1997.
FUTAI, M. M.. Theoretical and experimental study of unsaturated tropical soil behavior applied a gully case. Theses (PhD) - Universidade Federal do Rio de Janeiro, Rio de Janeiro, 2002, 559p (in portuguese).

GEERTSEMA, M.; TORRANCE, J. K.. Quick clay from the Mink Creek landslide near Terrace, British Columbia: Geotechnical properties, mineralogy, and geochemistry. Can Geotech J., v.42, p.907-918, 2005.

MITCHELL, B.. The Six Sigma appeal. Engineering Management Journal, v.2, n.1, p.41-47, 1992.

MITCHELL, J. K.. Fundamentals of soil behavior. 1 ed. New York: John Wiley \& Sons, Inc., 1976.

SANTOS, P. S.. Tecnologia de argilas, aplicada às argilas brasileiras. São Paulo: Edgar Blücher, 1975.

SKEMPTON, A. W.. The colloidal activity of clays. Proc. 3rd Int. Conf. Soil Mech. Found. Eng. Switzerland, v.1, p.57-61, 1953.

SUGUIO, K.. Geologia Sedimentar. São Paulo: Edgar Blücher, 2003.

TASSI, M.. Estudo sobre recalques em camada de solo mole submetida a 18 anos de compressão unidimensional - 0 caso Terra Encantada. Dissertação (Mestrado) - Universidade Federal do Rio de Janeiro, Rio de Janeiro, 2015.

TORRANCE, J. K.. A laboratory investigation of the effect of leaching on the compressibity and shear strength of Norwegin marine clays. Geotechnique, v.24, n.2, p.155-173, 1975.

VIEGAS, J. C.. Estudo hidrogeológico da bacia do rio Cabuçu - Zona Oeste do Município do Rio de Janeiro - RJ.

Dissertação (Mestrado) - Universidade Federal do Rio de Janeiro, Rio de Janeiro, 1976.

A CBPC - Companhia Brasileira de Produção Científica (CNPJ: 11.221.422/0001-03) detém os direitos materiais desta publicação. Os direitos referem-se à publicação do trabalho em qualquer parte do mundo, incluindo os direitos às renovações, expansões e disseminações da contribuição, bem como outros direitos subsidiários. Todos os trabalhos publicados eletronicamente poderão posteriormente ser publicados em coletâneas impressas sob coordenação da Sustenere Publishing, da Companhia Brasileira de Produção Científica e seus parceiros autorizados. Os (as) autores (as) preservam os direitos autorais, mas não têm permissão para a publicação da contribuição em outro meio, impresso ou digital, em português ou em tradução. 